\title{
Amyloid Deposition Is Linked to Aberrant Entorhinal Activity among Cognitively Normal Older Adults
}

\author{
Willem Huijbers, ${ }^{1,2,3}$ Elizabeth C. Mormino, ${ }^{2,3}$ Sarah E. Wigman, ${ }^{1,2,3}$ Andrew M. Ward, ${ }^{1,2,3}$ Patrizia Vannini, ${ }^{1,2,3}$ \\ Donald G. McLaren, ${ }^{2,3}$ J. Alex Becker, ${ }^{2,3}$ Aaron P. Schultz, ${ }^{2,3}$ Trey Hedden, ${ }^{2,4}$ Keith A. Johnson, , ${ }^{1,3,4}$ \\ and Reisa A. Sperling ${ }^{1,2,3}$ \\ ${ }^{1}$ Center for Alzheimer Research and Treatment, Department of Neurology, Brigham and Women's Hospital, Harvard Medical School, Boston, \\ Massachusetts 02115, ${ }^{2}$ Athinoula A. Martinos Center for Biomedical Imaging, Department of Radiology, Massachusetts General Hospital, Charlestown, \\ Massachusetts 02129, ${ }^{3}$ Harvard Aging Brain Study, Department of Neurology, and ${ }^{4}$ Department of Radiology, Massachusetts General Hospital, Harvard \\ Medical School, Boston, Massachusetts 02114
}

\begin{abstract}
Normal aging is often difficult to distinguish from the earliest stages of Alzheimer's disease. Years before clinical memory deficits manifest, amyloid- $\beta$ deposits in the cortex in many older individuals. Neuroimaging studies indicate that a set of densely connected neocortical regions, referred to as the default network, is especially vulnerable to amyloid- $\beta$ deposition. Yet, the impact of amyloid- $\beta$ on age-related changes within the medial temporal lobe (MTL) memory system is less clear. Here we demonstrate that cognitively normal older humans, compared with young adults, show reduced ability to modulate hippocampal activations and entorhinal deactivations during an episodic memory task. Among older adults, amyloid- $\beta$ deposition was associated with failure to modulate activity in entorhinal cortex, but not hippocampus. Furthermore, we show that entorhinal regions demonstrating amyloid- $\beta$-related dysfunction are directly connected to the neocortical regions of the default network. Together these findings link neocortical amyloid- $\beta$ deposition to neuronal dysfunction specifically in entorhinal cortex, while aging is associated with more widespread functional changes across the MTL.
\end{abstract}

Key words: amyloid; default network; entorhinal cortex; fMRI; memory; preclinical Alzheimer's disease

\section{Introduction}

Advanced aging is associated with functional decline in the medial temporal lobe (MTL) and episodic memory (Park et al., 2002; Du et al., 2003; Small et al., 2011). Assessments of normal aging may be confounded by occult Alzheimer's disease (AD) pathology, as the pathology of $\mathrm{AD}$ begins decades before clinical memory deficits manifest (Braak and Braak, 1991; Price et al., 2009; Nelson et al., 2012). Approximately 30\% of cognitively normal older adults over age 65 harbor elevated levels of amyloid- $\beta$ deposition, as estimated by positron emission tomography (PET) (Mintun et al., 2006; Aizenstein et al., 2008; Jagust et

Received July 22, 2013; revised Feb. 14, 2014; accepted March 6, 2014.

Author contributions:W.H., T.H., K.A.J., and R.S. designed research;W.H., E.C.M., S.E.W., A.M.W., P.V., D.M., and J.A.B. performed research; A.S. and K.A.J. contributed unpublished reagents/analytic tools; W.H., A.M.W., J.A.B., A.S., and R.S. analyzed data; W.H., E.C.M., A.M.W., T.H., and R.S. wrote the paper.

This research was supported by European Molecular Biology Organization Grant ALTF 318-2011 (W.H.); Marie Curie Fellowship FP7-PEOPLE-2007-4-1-IOF (P.V.); National Institutes of Health Grants F32 AG044054 (E.C.M.), F32 AG042228 (D.M.), K01 AG040197 (T.H.), K24 AG035007 (R.S.), R01 AG027435 (R.S.), P01AG036694 (R.S./K.A.J.), and P50AG005134 (R.S.); and the Alzheimer's Association Grant IIRG-06-27374 (K.A.J.). This research was performed in whole or in part at the Athinoula A. Martinos Center for Biomedical Imaging at the Massachusetts General Hospital, using resources provided by the Center for Functional Neuroimaging Technologies Grant P41EB015896, a P41 Biotechnology Resource Grant supported by the National Institute of Biomedical Imaging and Bioengineering, National Institutes of Health. The content is solely the responsibility of the authors and does not necessarily represent the official views of the National Institute on Aging or the National Institutes of Health.

The authors declare no competing financial interests.

Correspondence should be addressed to Willem Huijbers, Center for Alzheimer Research and Treatment, 221 Longwood Avenue BL-104, Boston, MA 02115. E-mail: huijbers@nmr.mgh.harvard.edu.

DOI:10.1523/JNEUROSCI.3579-13.2014

Copyright $\odot 2014$ the authors $\quad 0270-6474 / 14 / 345200-11 \$ 15.00 / 0$ al., 2010; Rowe et al., 2010; Resnick and Sojkova, 2011). Current models suggest that these older adults are at increased risk of developing AD dementia (Sperling et al., 2011; Jack et al., 2013; Knopman et al., 2013b; Roe et al., 2013; Villemagne et al., 2013).

Neuroimaging studies using PET and fMRI indicate that a set of densely connected and metabolically active brain regions - the default network — is especially vulnerable to early amyloid- $\beta$ deposition (Lustig et al., 2003; Buckner et al., 2005). Amyloid- $\beta$ deposition is associated with aberrant default-network activity in neocortical regions during memory encoding (Sperling et al., 2009; Kennedy et al., 2012) and at rest (Hedden et al., 2009; Sheline et al., 2010; Mormino et al., 2011). However, the relationship between neocortical amyloid- $\beta$ deposition and dysfunction of the MTL memory system remains to be elucidated.

The hippocampus and entorhinal cortex support episodic memory and are vulnerable to both normal aging and AD processes (Fernández et al., 1999; Petersen et al., 2000; Rodrigue and Raz, 2004; Small et al., 2011). Tau-aggregation is thought to occur in entorhinal cortex before amyloid- $\beta$ deposits in neocortex (Braak and Braak, 1991; Nelson et al., 2012), whereas models of AD suggest that damage to hippocampus occurs downstream of amyloid- $\beta$ deposition (Becker et al., 2011; Serrano-Pozo et al., 2011; Jack et al., 2013). Thus, many cognitively older adults might show dysfunction in entorhinal cortex in the absence of hippocampal dysfunction. Furthermore, functional connectivity studies indicate that the default network is more strongly connected to entorhinal cortex than to hippocampus (Kahn et al., 
Table 1. Demographics of young and older adults included in the fMRI study

\begin{tabular}{lcl}
\hline Label & Young adults & Older adults \\
\hline$n$ & 21 & 48 \\
Age (years) & $25.3 \pm 0.59$ & $75.6 \pm 0.86$ \\
Gender & $60 / 15 q$ & $240 / 24 \bigcirc$ \\
Years of education & $16.4 \pm 0.31$ & $16.9 \pm 0.37$ \\
Memory $\left(d^{\prime}\right)$ & $1.98 \pm 0.11$ & $1.08 \pm 0.05$ \\
Hippocampal volume $\left(\mathrm{mm}^{3}\right)$ & $8707 \pm 146$ & $7522 \pm 200$ \\
Entorhinal thickness $(\mathrm{mm})$ & $3.78 \pm 0.06$ & $3.58 \pm 0.06$
\end{tabular}

$n$, Number of subjects. Memory performance $\left(d^{\prime}\right)$ was defined by the memory task inside the fMRI scanner.

2008; Lacy and Stark, 2012; Libby et al., 2012; Ward et al., 2014). Therefore, entorhinal cortex might be especially vulnerable to amyloid- $\beta$-related dysfunction of the default network.

Here, we test the hypothesis that amyloid- $\beta$ deposition is associated with specific functional changes within entorhinal cortex among clinically normal older adults. First, we identify MTL regions that show task-induced activations and deactivations in young and older adults during an episodic memory task, and investigate the effect of aging on the ability to modulate MTL activity. Second, we examine the influence of amyloid- $\beta$ deposition on hippocampus and entorhinal activity among older adults. Finally, we examine age- and amyloid- $\beta$-related changes in entorhinal connectivity to the default network, to test the postulate that entorhinal dysfunction and disconnection is associated with amyloid- $\beta$ deposition in older individuals, even in the absence of clinically detectable memory impairment.

\section{Materials and Methods}

Sixty-nine healthy adults ( 21 young adults: 6 male/15 female; 48 older adults: 24 male/24 female) were recruited from the Harvard Aging Brain Study. All were native English speakers, had normal or corrected-tonormal vision, and were right-handed (Table 1). None had a history of psychiatric or neurological disorders or reported taking medications that affect the CNS. Written informed consent was obtained from every adult before experimental procedures and the study was approved by, and conducted in accordance with, the Partners Human Research Committee at the Brigham and Women Hospital and Massachusetts General Hospital (Boston, MA). Structural MRI, resting-state fMRI, and taskrelated fMRI data were collected on each subject. These data have not been previously published in any form. Without consideration to the fMRI data, equal numbers of older adults with high and low amounts of amyloid- $\beta$ deposition were selected to ensure a similar age range in both groups.

PET acquisition and analysis. We estimated amyloid- $\beta$ deposition of the older adults using PET with Pittsburg compound-B (PiB; $N$-methyl$\left[{ }^{11} \mathrm{C}\right]-2$ (4-methylaminophenyl)-6-hydroxybenzothiazole). The tracer was prepared and implemented as described previously (Mathis et al., 2002; Johnson et al., 2007). ${ }^{11} \mathrm{C}-\mathrm{PiB}(10-15 \mathrm{mCi})$ was injected as a bolus, followed by $60 \mathrm{~min}$ of dynamic PET acquisition. PET images were acquired using an HR + PET camera (Siemens) operating in threedimensional mode (63 image planes; $15.2 \mathrm{~cm}$ axial field of view; $5.6 \mathrm{~mm}$ transaxial resolution; $2.4 \mathrm{~mm}$ slice interval; 69 frames: $12 \times 15 \mathrm{~s}, 57 \times$ $60 \mathrm{~s})$. PET data were reconstructed and corrected for attenuation with vendor-provided software. Each frame was evaluated for head motion and adequate count statistics. Using Logan's graphical analysis method, we calculated $\mathrm{PiB}$ retention expressed as the distribution volume ratio, using a gray matter cerebellum reference region from the AAL atlas (Price et al., 2005). Each subject's amyloid- $\beta$ status was calculated using a global distribution volume ratio from a set of neocortical regions that comprised most of the association cortex, including frontal, lateral parietal, lateral temporal, and retrosplenial cortex. Subjects were classified as either low $(\mathrm{A} \beta-)$ or high $(\mathrm{A} \beta+)$ amyloid- $\beta$ groups, based on a prior mean cortical threshold of 1.15 (Hedden et al., 2009; Vannini et al., 2013).

We also evaluated local $\mathrm{PiB}$ retention within the entorhinal cortex by extracting the average $\mathrm{PiB}$ retention from left and right medial temporal regions. Consistent with multiple previous amyloid-imaging studies (Mathis et al., 2002; Johnson et al., 2007), the entorhinal regions showed relatively lower $\mathrm{PiB}$ retention and smaller differences between $\mathrm{A} \beta$ - (entorhinal $=1.10)$ and $\mathrm{A} \beta+($ entorhinal $=1.18)$ compared with the neocortex $\mathrm{A} \beta-($ neocortex $=1.09)$ and $\mathrm{A} \beta+($ neocortex $=1.33$; interaction $p=0.0011$ ). We used the cortical aggregate of neocortical regions to identify clinically normal older adults, as this is commonly used to define individuals who may be in the preclinical stages of $\mathrm{AD}$, at a threshold that corresponds to sufficient plaque burden to meet CERAD plaque criteria for neuropathological Alzheimer's disease (Clark et al., 2011). However, it is likely that neocortical amyloid levels are also reflective of MTL amyloid burden, as entorhinal $\mathrm{PiB}$ retention was strongly correlated with the estimate from neocortical regions $(r=0.88)$.

MRI data acquisition. MRI data were collected on a Siemens TrioTim 3.0 tesla scanner (Siemens Medical Systems) equipped with a 12-channel phased-array head coil. High-resolution T1-weighted anatomical images were acquired using an MPRAGE with the following parameters: 256 sagittal slices, repetition time $(\mathrm{TR})=2300 \mathrm{~ms}$, echo time $(\mathrm{TE})=2.95 \mathrm{~ms}$, inversion time $=900 \mathrm{~ms}$, flip angle $(\mathrm{FA})=9^{\circ}, \mathrm{FOV}=270 \times 253 \mathrm{~mm}$, matrix $=256 \times 240$, voxel size $=1.05 \times 1.05 \times 1.2 \mathrm{~mm}$. Task-related BOLD data were acquired using a $\mathrm{T} 2{ }^{\star}$-weighted gradient-echo planar imaging (EPI) sequence. We acquired 6 time series of 180 volumes, excluding 4 dummies. Each volume consisted of 33 axial slices, $3 \mathrm{~mm}$ thickness, with a skip of $0.8 \mathrm{~mm}$; TR $=2000 \mathrm{~ms}$; TE $=30 \mathrm{~ms}$; FA $=90^{\circ}$, $\mathrm{FOV}=192 \times 192 \mathrm{~mm}$, matrix $=64 \times 64$, effective voxel size $=3 \times 3 \times$ $3.8 \mathrm{~mm}$. After the event-related task, we acquired a resting-state time series of 120 volumes, 47 axial slices in interleaved order, with $\mathrm{TR}=3000$ $\mathrm{ms} ; \mathrm{TE}=30 \mathrm{~ms} ; \mathrm{FA}=85^{\circ}, \mathrm{FOV}=216 \times 216 \mathrm{~mm}$, matrix $=72 \times 72$, voxel size $=3 \times 3 \times 3 \mathrm{~mm}$.

During the event-related fMRI task, participants learned novel and remembered previously seen face/name pairs, in a design identical to that of Huijbers et al. (2013). While inside the fMRI scanner, adults observed 300 faces with an emotionally neutral expression paired with fictional first names. A total of $50 \%$ of face/name pairs were novel, $40 \%$ of face/ name pairs were studied before scanning, and $10 \%$ of face/name pairs were studied but presented in a different combination (re-paired). Memory for novel faces presented during scanning was tested following the scan session. The paradigm was designed and generated using the Psychophysics Toolbox (Brainard, 1997) and MATLAB (MathWorks). Visual stimuli were projected to a screen positioned at the head of the magnet bore and reflected onto a mirror attached to the head coil. Responses were made via an MRI-compatible key press device held in the subject's right hand. Head motion was restrained with foam-padded clamps. Earplugs and noise-reduction headphones were used to reduce scanner noise. The task consisted of six runs. In each run, 50 stimuli were shown for $3750 \mathrm{~ms}$, each with an intertrial interval between 250 and $10,250 \mathrm{~ms}$ (average $3300 \mathrm{~ms}$ ), during which a fixation cross was presented at the center of the screen. The fixation times and trial order were optimized using optseq2 (Dale et al., 1999).

MRI data analysis. The functional MRI images were preprocessed and analyzed using SPM8 (University College London, http://www.fil.ion. ucl.ac.uk/spm). Functional MRI data were slice time-corrected, realigned, normalized to the MNI152 EPI template, resampled to $3 \times 3 \times$ $3 \mathrm{~mm}$ voxels, and smoothed with $8 \mathrm{~mm}$ full-width half-maximum Gaussian kernel. For the task-based fMRI analysis, we used the general linear model (GLM) as implemented in SPM8. Face/name pairs were modeled based on performance: retrieval hit, retrieval miss, re-paired hit, re-paired miss, correct rejection, and false alarm. To quantify memory performance, we calculated a $d^{\prime}$ score using $Z$ (retrieval hit/[retrieval hit + retrieval miss $])-Z($ false alarm/[false alarm + correct rejection]; MacMillan and Creelman, 2005). The correct rejection and false alarms were further modeled based on postscan subsequent memory performance (tested following the scan) as encoding hit, encoding miss, or re-paired. Omissions were coded as separate events, resulting in a total of 11 unique trial types. The onsets for these events were convolved with the canonical hemodynamic response function using response times, collected during the scan-phase, as duration. Additionally, the models included regressors for the motion parameters, bad-volume regressors, and a high-pass filter $(1 / 128 \mathrm{~Hz})$. Scans were coded as bad-volumes when 


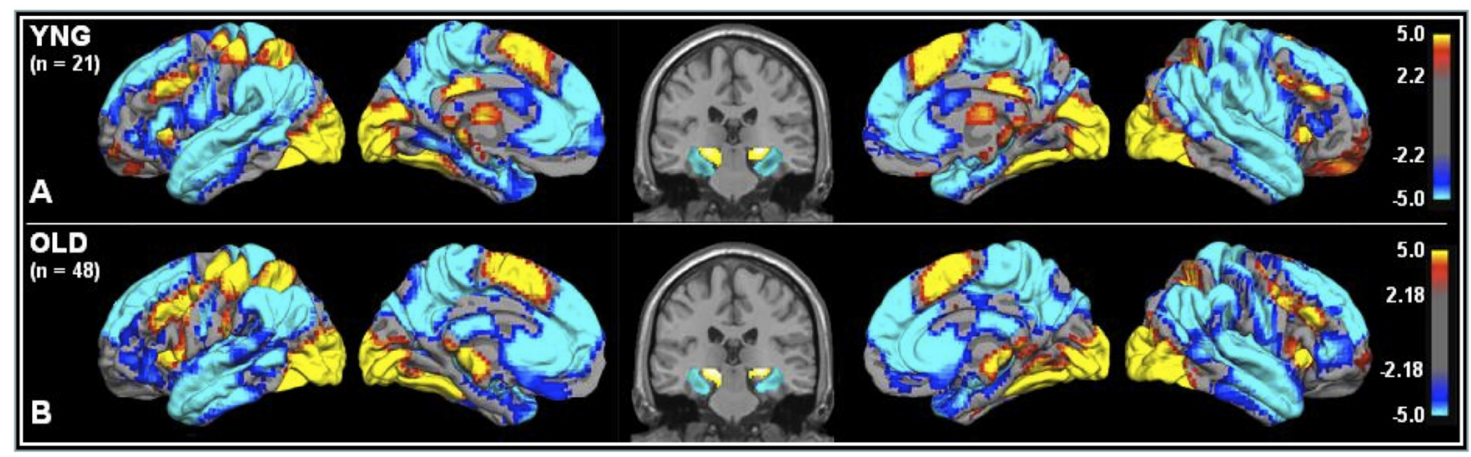

Figure 1. Task-induced activations and deactivations in young $(\boldsymbol{A})$ and older $(\boldsymbol{B})$ adults. Task-induced activations (task $>$ fixation) in red/yellow and task-induced deactivations (fixation $>$ task) in blue. Statistical values are thresholded at $p<0.05$ (FDR-corrected, minimum cluster extent 10 voxels) projected on the cortical surface of the left and right hemisphere. In the middle, a coronal slice to show hippocampal activations (red/yellow) and entorhinal deactivations (blue). Top shows a statistical activation map from 21 young subjects. Bottom shows activation map from 48 older subjects.

movement to the previous scans exceeded $0.75 \mathrm{~mm}$ or 1.5 degrees in one direction. Individual $\beta$-maps were calculated by contrasting all task events versus fixation. Thus, task-induced activations and deactivations were identified regardless of the memory condition or task performance.

We used SPM8 in combination with in-house developed MATLAB scripts to analyze the group-level data (GLM-Flex, Harvard Aging Brain Study, Martinos Center, MGH, Boston, MA, http://nmr.mgh. harvard.edu/harvardagingbrain/People/AaronSchultz/Aarons_Scripts). These GLM scripts allow modeling of the within- and between-group effects using a single model. Group analyses included a between-groups ANOVA of young versus older adults and a between-groups ANOVA of $\mathrm{A} \beta$ - versus $\mathrm{A} \beta+$ older adults. Statistical group maps were projected to the cortical surface using FreeSurfer 5.1 via a standard MNI to the FreeSurfer average template transformation (http://surfer.nmr.mgh.harvard. edu) or were resliced to $2 \times 2 \times 2 \mathrm{~mm}$ voxels and overlaid on the standard SPM8 individual T1-weighted volume.

The anatomical T1-weighted images (MPRAGE) were analyzed using FreeSurfer v5.1 (http://surfer.nmr.mgh.harvard.edu). We performed minimal manual editing for quality control to ensure that non-brain structures were excluded from the pial surface by a single rater (A.M.W.). Subsequent processing steps used default parameters without manual intervention, including estimation of hippocampal volume and entorhinal cortical thickness.

The resting-state fMRI analysis was processed using SPM8 and inhouse developed MATLAB scripts. The first four volumes were dropped to reach signal equilibrium. The data were bandpass filtered between 0.01 and $0.08 \mathrm{~Hz}$, and nuisance regressors (and their first derivatives) for mean signal from the white matter, lateral ventricles, and global brain signals, and motion parameters were applied (Van Dijk et al., 2010). For each subject, we created seed-based correlation maps using an 8-mmdiameter spherical seed, located on the maxima of activation or deactivation identified by the between-subjects ANOVA. We used the peaks of the hippocampal activations and entorhinal deactivations in each age group (see Results) to define the seed locations. The correlation maps were transformed to a $Z$-score map using Fisher's $r$-to- $Z$ transform. Next, we used GLM-Flex to calculate connectivity maps in a $2 \times 2$ ANOVA with factors for the seeds in each hemisphere (left/right) and seeds in each MTL-region (hippocampus/entorhinal) and the main effects of connectivity across age groups $[p<0.05$, false discovery rate (FDR) corrected, minimum cluster size 10 voxels].

To quantify hippocampus/default-network and entorhinal/defaultnetwork connectivity, we extracted the connectivity values from the whole-brain connectivity maps described above. We extracted the values from $8 \mathrm{~mm}$ spherical a priori regions of interest (ROIs) within the neocortical nodes of the default-network, including the medial prefrontal cortex $\left(\mathrm{MNI}_{x, y, z}=0,52,-6\right)$, posteromedial cortex $\left(\mathrm{MNI}_{x, y, z}=0,-53\right.$, $26)$, and the average from both left $\left(\mathrm{MNI}_{x, y, z}=-48,-62,36\right)$ and right $\left(\mathrm{MNI}_{x, y, z}=46,-62,32\right)$ angular gyrus (Hedden et al., 2009; Van Dijk et al., 2010). For each adult, we averaged the ROI values and obtained a single value that represented hippocampus/default-network or entorhinal/ default-network connectivity.

\section{Results}

On average, young adults correctly recognized $63 \pm 4.3 \%$ of the previously seen face/name pairs and correctly rejected $92 \pm 1.5 \%$ of the novel pairs. Older adults correctly recognized $57 \pm 2.6 \%$ of the previously seen face/name pairs and correctly rejected $77 \pm 2.0 \%$ of the novel pairs [see Table 1 for memory performance $\left.\left(d^{\prime}\right)\right]$. A between-groups $t$ test confirmed that younger adults showed better memory performance compared with older adults $(p<0.001)$. Young adults had larger hippocampal volumes $(p<0.001)$ and thicker entorhinal cortices $(p=0.015)$ compared with older adults.

\section{Task-induced activations and deactivations}

We first investigated task-induced activations and deactivations common to young and older adults at the whole-brain level. In both age groups, we found task-induced activations (task $>$ fixation) in the dorsolateral prefrontal cortex, supramarginal gyrus, supplementary and primary motor cortex, visual cortex, and hippocampus (Fig. 1, $p<0.05$, FDR-corrected), a set of regions oftentimes described as a "task-positive network" (Fox et al., 2005). Within the MTL, the young adults showed activations in the left $\left(\mathrm{MNI}_{x, y, z}=-22,-28,-7\right)$ and right hippocampus $\left(\mathrm{MNI}_{\mathrm{x}, y, z}=23,-28,-4\right)$. Similarly, the older adults showed activation in the left $\left(\mathrm{MNI}_{x, y, z}=-16,-28,-7\right)$ and right $\left(\mathrm{MNI}_{x, y, z}=23,-28,-4\right)$ hippocampus. In both age groups, we found task-induced deactivations (fixation $>$ task) in the medial prefrontal cortex, posteromedial cortex, angular gyrus, and parahippocampus/entorhinal cortex (Fig. 1, $p<0.05$, FDRcorrected), a set of regions often described as the default network (Raichle et al., 2001). Within the MTL, the young adults showed deactivations in the left $\left(\mathrm{MNI}_{x, y, z}=-28,-13,-25\right)$ and right $\left(\mathrm{MNI}_{x, y, z}=29,-25,-19\right)$ entorhinal cortex. Similarly, the older adults showed deactivations in the left $\left(\mathrm{MNI}_{x, y, z}=-33,-31\right.$, $-16)$ and right $\left(\mathrm{MNI}_{x, y, z}=32,-22,-19\right)$ entorhinal cortex.

\section{Age-related changes in medial temporal lobe functional activity}

Next, we examined the difference in MTL activity between young and older adults. To determine whether aging reduces taskinduced hippocampal activations and entorhinal cortex deactivations, we isolated the patterns of activity within the MTL by 


\section{Hippocampal activations}
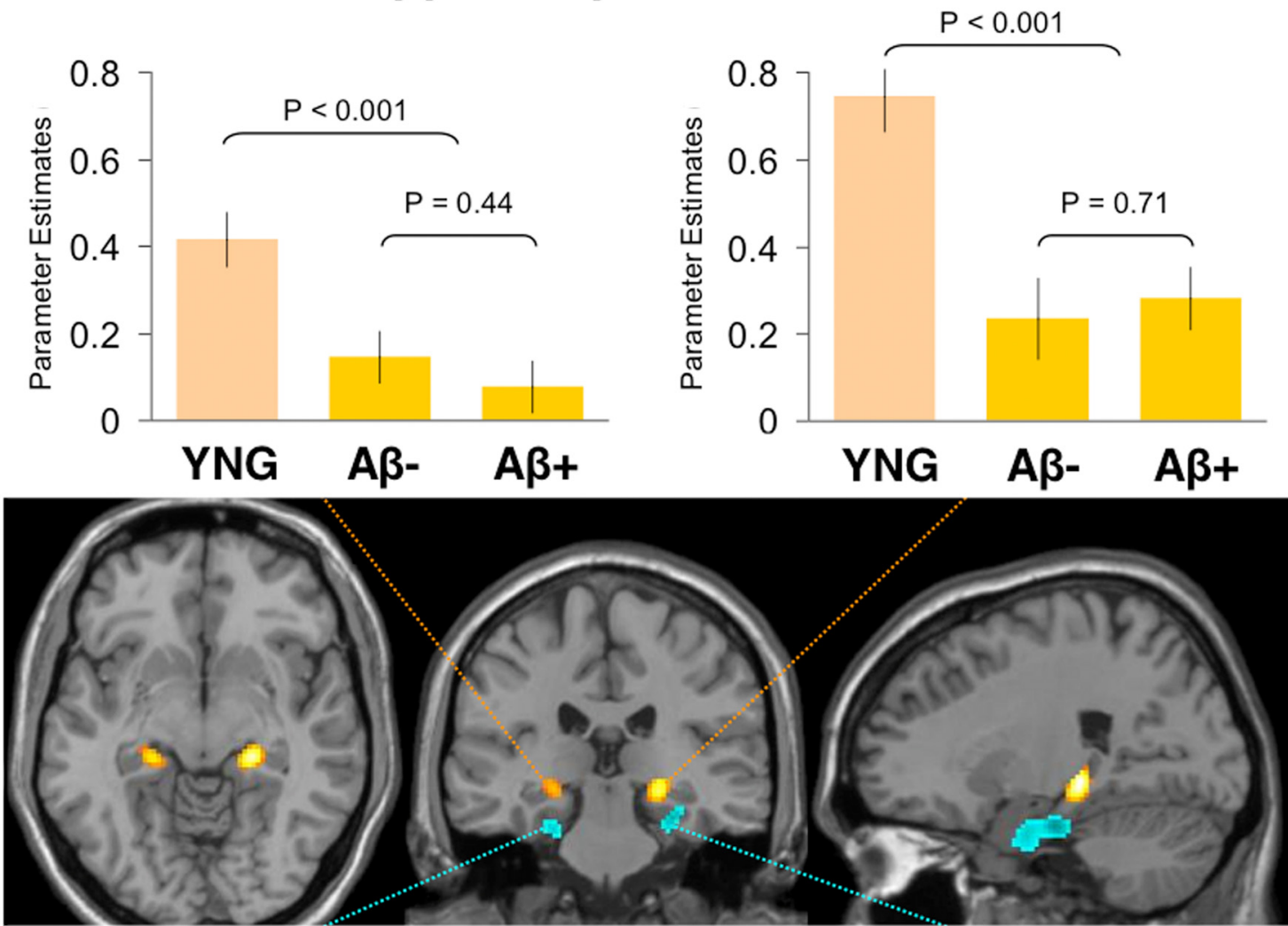

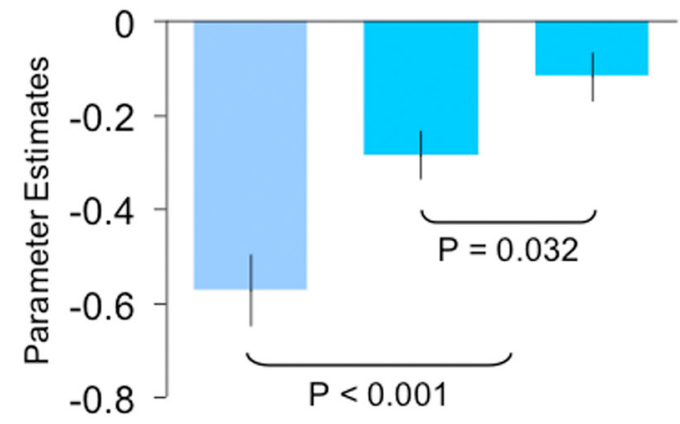

YNG $\quad A \beta-\quad A \beta+$

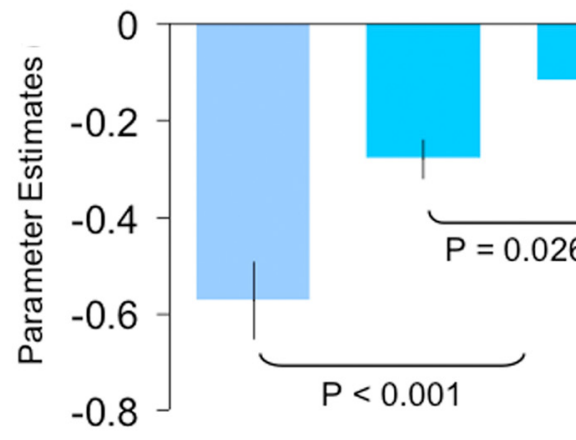

YNG $\quad A \beta-\quad A \beta+$

\section{Entorhinal deactivations}

Figure 2. Age- and amyloid- $\beta$-related difference in MTL activity. Task-induced activations (task $>$ fixation) in bilateral hippocampus (red/yellow) and task-induced deactivations (fixation $>$ task) in the bilateral entorhinal cortex (blue) as defined by the difference between young and older adults ( $p<0.05$, FDR-corrected, minimum cluster extent 10 voxels). Bar graphs show average activation plotted separately in young (YNG) and older adults with low (A $\beta-$ ) and high ( $\mathrm{A} \beta+)$ amounts of amyloid- $\beta$ deposition. Top, Activations in the left and right hippocampus showed no significant difference between $\mathrm{A} \beta$ - and $\mathrm{A} \beta+$ older adults. Bottom, Deactivations in the left $(p=0.032)$ and right $(p=0.026)$ entorhinal cortex were significantly reduced in $\mathrm{A} \beta+0$ older adults. Comparisons involving young adults indicate the difference between young and the average of all older adults.

masking the whole-brain statistical maps $(p<0.05$, FDRcorrected) with an anatomical ROI comprising the bilateral hippocampus and parahippocampus (see description of localization of entorhinal cortex below; Maldjian et al., 2003). Within hippocampus (Figs. 1 and 2), we found activations in both age groups. When comparing the older and young adults, we found an age-related reduction of activation in both the left $\left(\mathrm{MNI}_{x, y, z}=\right.$ $\left.-25,-31,-4 / T_{\max }=3.95\right)$ and right $\left(\mathrm{MNI}_{x, y, z}=20,-28\right.$, $\left.-4 / T_{\max }=4.45\right)$ hippocampus. Within the parahippocampus region (Fig. 2), we found an age-related reduction of deactivations localized to the left $\left(\mathrm{MNI}_{x, y, z}=-25,-25,-25 / T_{\max }=\right.$ $4.40)$ and right $\left(\mathrm{MNI}_{x, y, z}=26,-25,-22 / T_{\max }=4.68\right)$ entorhi- nal cortex. Within hippocampus we found no age-related increases in activation (older adults $>$ young adults), and within entorhinal cortex we did not find age-related increases in deactivations.

\section{Localization of age-related changes in functional activity}

To anatomically localize the MTL activity clusters in relation to the anatomical structure, we used the SPM anatomy toolbox (v1.8) (Eickhoff et al., 2007). Here, we list the primary region of overlap for each cluster (the largest unlisted region had 19.5\% overlap with the thalamus). The left hippocampal cluster $\left(\mathrm{MNI}_{x, y, z}=-25,-31,-4\right)$ had an overlap of $49.8 \%$ with the 
Table 2. Demographics of $A \boldsymbol{\beta}-$ and $A \boldsymbol{\beta}+$ older adults

\begin{tabular}{|c|c|c|c|}
\hline Label & $A \beta-$ & $A \beta+$ & $p$ values \\
\hline$n$ & 24 & 24 & \\
\hline Age (years) & $74.4 \pm 1.15$ & $76.8 \pm 1.27$ & $p=0.18$ \\
\hline Gender & 10 రే / 14 우 & 14 oै/ 10 우 & $p=0.25$ \\
\hline APOE4 status & $20 \epsilon 4-/ 3 \epsilon 4+$ & $10 \epsilon 4-/ 13 \epsilon 4+$ & $p=0.002$ \\
\hline Years of education & $16.8 \pm 0.59$ & $16.9 \pm 0.47$ & $p=0.91$ \\
\hline VIQ & $123.2 \pm 1.54$ & $123.4 \pm 1.16$ & $p=0.93$ \\
\hline CDR & 0 & 0 & \\
\hline MMSE & $29 \pm 0.16$ & $29.3 \pm 0.18$ & $p=0.30$ \\
\hline BNT & $28.3 \pm 0.47$ & $27.9 \pm 0.47$ & $p=0.52$ \\
\hline Memory $\left(d^{\prime}\right)$ & $1.14 \pm 0.37$ & $1.02 \pm 0.27$ & $p=0.27$ \\
\hline Hippocampal volume $\left(\mathrm{mm}^{3}\right)$ & $7526 \pm 161$ & $7518 \pm 213$ & $p=0.98$ \\
\hline Entorhinal thickness (mm) & $3.62 \pm 0.06$ & $3.55 \pm 0.06$ & $p=0.48$ \\
\hline PiB (neocortex) & $1.09 \pm 0.01$ & $1.33 \pm 0.04$ & $p<0.001$ \\
\hline
\end{tabular}

Brain measures include FreeSurfer-calculated hippocampal volume, entorhinal thickness, and Pittsburgh compound-B (PiB) amyloid retention within the neocortical regions of interest. Note that APOE4 status was identified for 46 of 48 older adults, and $p$ values reflect two-samples $t$ test between $A \beta-$ and $A \beta+$ older adults. $n$, Number of subjects; VIQ, verbal intelligence quotient; CDR, clinical dementia rating; MMSE, mini-mental state exam; BNT, Boston Naming Test.

subiculum, whereas the right hippocampal cluster $\left(\mathrm{MNI}_{x, y, z}=\right.$ $20,-28,-4)$ had an overlap of $47.0 \%$ with the subiculum. The left parahippocampal cluster $\left(\mathrm{MNI}_{x, y, z}=-25,-25,-25\right)$ had an overlap of $53.0 \%$ with entorhinal cortex, whereas the right parahippocampal cluster $\left(\mathrm{MNI}_{x, y, z}=26,-25,-22\right)$ had an overlap of $44.4 \%$ with entorhinal cortex. Thus, the age-related differences in activations were predominantly located in hippocampus, whereas age-related differences in deactivations were predominantly located in entorhinal cortex.

\section{Amyloid- $\boldsymbol{\beta}$ augments age-related changes in entorhinal cortex}

Based on the amyloid- $\beta$ imaging data, we classified older adults into groups with low $(\mathrm{A} \beta-)$ and high $(\mathrm{A} \beta+)$ amounts of amyloid- $\beta$ deposition (Hedden et al., 2009; Sperling et al., 2009). These groups did not differ across examined neuropsychological data, memory performance $\left(d^{\prime}\right)$ on the fMRI task, and FreeSurfer-based estimates of hippocampal volume and entorhinal thickness (Table 2).

First, we examined the effect of aging in the absence of amyloid deposition. Using the same MTL clusters that showed reduced activity when comparing young adults versus all older adults, we now compared young adults versus $\mathrm{A} \beta-$ older adults. Both left $(p=0.004)$ and right $(p<0.001)$ hippocampus showed reduced activity with aging in the absence of amyloid deposition, indicating an effect of age. Similarly, both the left $(p=0.004)$ and right $(p=0.002)$ entorhinal cortex showed reduced deactivation in the absence of amyloid deposition, indicating that age influences hippocampal and entorhinal activity.

To identify whether deposition of amyloid- $\beta$ is associated with the age-related changes in MTL activity, we again examined the same MTL clusters. The average $\beta$-weights within these MTL clusters were extracted for older adults and separated into $\mathrm{A} \beta-$ and $\mathrm{A} \beta+$ groups. One-sample $t$ tests confirmed that within all older adults, the left $(p=0.013)$ and right $(p<0.001)$ hippocampi were activated and that the left $(p<0.001)$ and right $(p<0.001)$ entorhinal cortices were deactivated. However, between-groups $t$ tests indicated no significant difference between $\mathrm{A} \beta-$ and $\mathrm{A} \beta+$ groups for activation in the left $(p=0.44)$ or right hippocampus $(p=0.71)$. In contrast, both the left $(p=$ $0.032)$ and right entorhinal cortex $(p=0.026)$ showed reduced deactivations in $A \beta+$ compared with $A \beta$ - older adults (Fig. 2).

\section{Age- and amyloid- $\beta$-associated alterations across memory processes}

We then conducted an analysis to examine whether age- and amyloid-related effects were similar across memory encoding and retrieval processes and performance. Therefore, we separated events based on memory phase (encoding/retrieval) and memory performance (hit/miss). Next, we again used the same MTL clusters that showed reduced levels of activity in older compared with young adults and extracted the average $\beta$-weights for encoding hit, encoding miss, retrieval hit, and retrieval miss within the MTL clusters (Fig. 3). For illustrative purposes, we averaged across the cluster in the left and right hemispheres. To further examine the effect of amyloid, we used an ANOVA, including the factors amyloid- $\beta$ status $(\mathrm{A} \beta-/ \mathrm{A} \beta+)$, memory phase (encoding/retrieval), memory performance (hit/miss), and hemisphere (left/right). The ANOVA indicated a main effect $(p=0.0044)$ of amyloid- $\beta$ status and a main effect of task performance $(p=$ $0.0051)$ for entorhinal activity. Critically, the ANOVA indicated no interaction between amyloid- $\beta$ status, memory phase, memory performance, or hemisphere.

Post hoc $t$ tests, using the average of left and right hemisphere, indicated that hippocampal activations were reduced by aging across all memory phase and performance conditions (young vs older: encoding hit, $p<0.001$, encoding miss, $p=0.003$, retrieval hit, $p<0.001$, retrieval miss, $p<0.001)$. A second series of $p o s t$ hoc $t$ tests examined whether the effect of aging was also present in the absence of amyloid- $\beta$ deposition (young vs $\mathrm{A} \beta$ - older adults: encoding hit, $p<0.001$, encoding miss, $p=0.002$, retrieval hit, $p<0.001$, retrieval miss, $p<0.001)$. Hippocampal activity was not significantly different between $\mathrm{A} \beta-$ and $\mathrm{A} \beta+$ older adults across any conditions. Aging also reduced entorhinal deactivations across memory phase and performance conditions (young vs older adults: encoding hit, $p=0.014$, encoding miss, $p<$ 0.001 , retrieval hit, $p<0.001$, retrieval miss, $p<0.001$ ). Again, a second series of post hoc tests demonstrated that the effect of aging was also present in the absence of amyloid- $\beta$ deposition (young vs $\mathrm{A} \beta-$ older adults: encoding hit, $p<0.34$, encoding miss, $p=0.003$, retrieval hit, $p<0.001$, retrieval miss, $p<0.001$ ). We also observed an influence of amyloid- $\beta$ on entorhinal deactivations during encoding hit and retrieval hit conditions $(\mathrm{A} \beta-$ vs $\mathrm{A} \beta+$ : encoding hit, $p=0.006$, encoding miss, $p=0.16$, retrieval hit, $p=0.052$, retrieval miss, $p=0.43$ ). However, as mentioned, the ANOVA indicated no significant interaction between amyloid- $\beta$ status, memory phase, memory performance, or hemisphere. Thus, although individual follow-up comparisons reach significance, these analyses suggest a similar pattern of MTL activity across memory processes, where aging has a general effect on activity in both hippocampal and entorhinal cortex, but amyloid- $\beta$ deposition demonstrated a specific effect on entorhinal deactivations.

\section{Functional activity after controlling for apolipoprotein E4 status, age, gender, d' and gray matter}

We conducted several analyses to clarify whether age-related differences in MTL activity can be explained by memory performance $\left(d^{\prime}\right)$ or gray matter (hippocampal volume or entorhinal thickness). $d^{\prime}$ accounted for age-related changes in fMRI activity in the left $(p=0.009)$ but not the right $(p=0.20)$ hippocampus, and the left $(p=0.019)$ and right $(p=0.079)$ entorhinal cortex. Hippocampal volume did show a significant relation with agerelated changes in hippocampal activity. In contrast, entorhinal thickness showed an effect in the left $(p=0.015)$ and right $(p=$ 0.058 ) entorhinal cortex. However, when simultaneously con- 


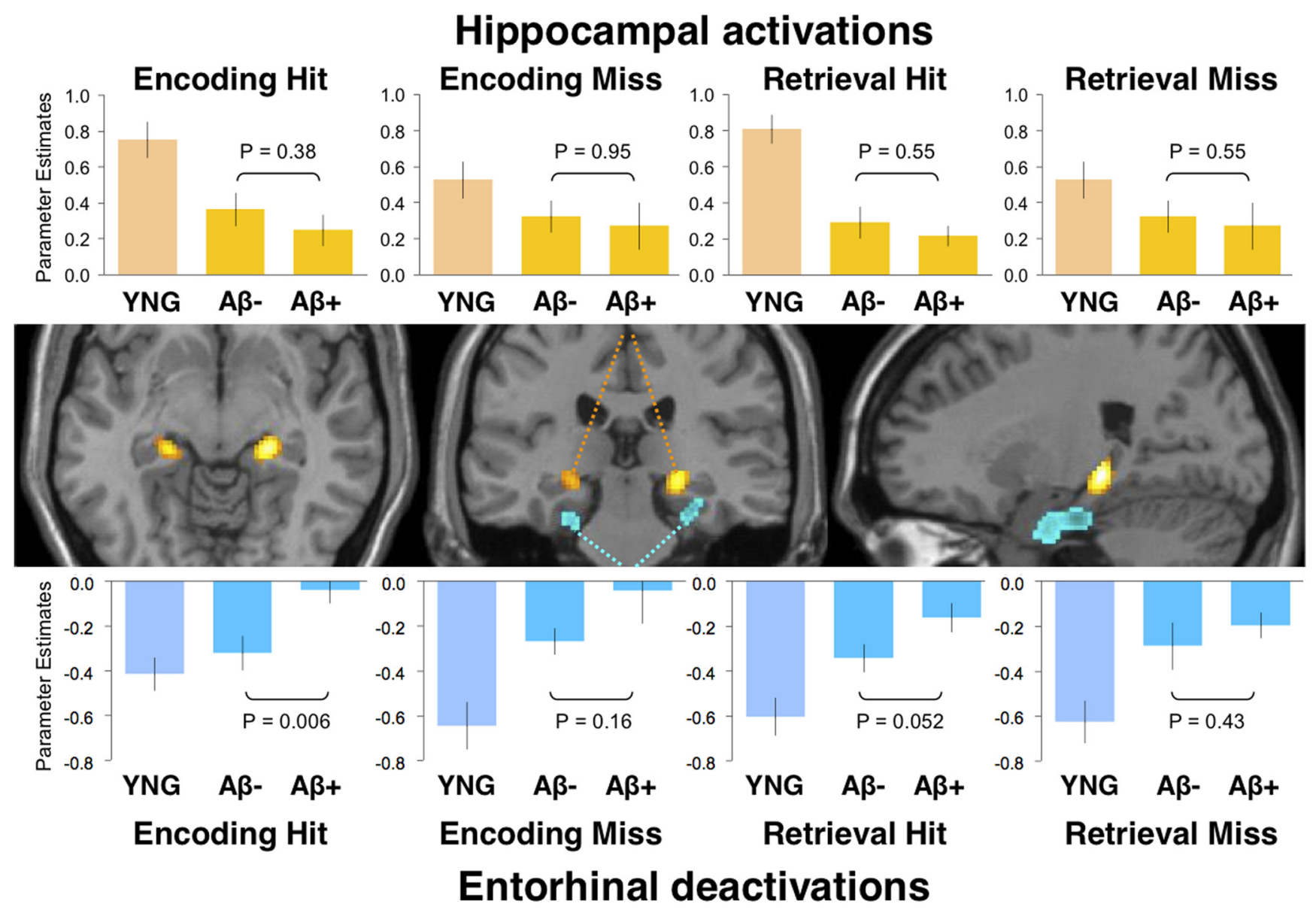

Figure 3. MTL activity separated by task condition. Task-induced activity in hippocampus (red/yellow) and task-induced deactivations (blue) in entorhinal cortex separated by task-condition. Bar graphs show averaged activity for encoding hit, encoding miss, retrieval hit, and retrieval miss in young (YNG) and older adults with low (A $\beta-$ ) and high ( $\beta+$ ) amounts of amyloid- $\beta$ deposition. Top shows activations averaged across the left and right hippocampus and demonstrated no significant differences between $A \beta-$ and $A \beta+$ older adults. Bottom shows deactivations, averaged across the left and right entorhinal cortex. Note that the pattern was similar across all task-conditions and an ANOVA revealed no significant interactions between amyloid- $\beta$ status and encoding/retrieval or hit/miss. Middle panel is reproduced from Figure 2.

trolling for these variables and the interactions, we still observed age-related differences in the left $(p<0.001)$ and right $(p<$ $0.001)$ hippocampus, as well as the left $(p<0.001)$ and right $(p<$ $0.001)$ entorhinal cortex. Thus, these analyses suggest that $d^{\prime}$ and regional gray matter only account for a portion of the age-related differences in MTL activity.

Next, we conducted an analysis to clarify whether the amyloid- $\beta$-related difference in entorhinal fMRI activity could be explained by apolipoprotein E4 (APOE4) status, age, gender, $d^{\prime}$, or entorhinal thickness (Table 3). For simplicity we averaged the activity in left and right hemisphere for both hippocampus and entorhinal cortex. When we simultaneously controlled for APOE4 status, age, gender, $d^{\prime}$, and entorhinal thickness, we still found amyloid-related difference in deactivations in the entorhinal cortex $(p=0.032)$, but not in the hippocampus $(p=0.26)$. Thus, amyloid- $\beta$-related functional changes in entorhinal cortex of older adults are evident, even accounting for APOE4 status, age, gender, $d^{\prime}$, and entorhinal thickness.

Functional connectivity of hippocampus and entorhinal cortex

To determine whether task-induced deactivations in entorhinal cortex occur in regions functionally connected to the default network, we analyzed resting-state fMRI data collected in the same scanning session. First, we calculated whole-brain functional connectivity maps based on seeds located in the peak activation in hippocampus and peak deactivation in entorhinal cortex for each age group. Next, we used repeated-measures ANOVA with a factor for seed-region (hippocampal/entorhinal) and hemisphere (left/right) to visualize hippocampal and entorhinal connectivity across both age groups (Fig. 4, $p<0.05$, FDR-corrected). These maps demonstrate that entorhinal cortex is connected to neocortical regions of the default network, including the medial prefrontal cortex $\left(\mathrm{MNI}_{x, y, z}=2,44,-10\right)$, posteromedial cortex $\left(\mathrm{MNI}_{x, y, z}=-1,-46,29\right)$, and left $\left(\mathrm{MNI}_{x, y, z}=-40,-73,-35\right)$ and right $\left(\mathrm{MNI}_{x, y, z}=50,-70,38\right)$ lateral parietal cortex. In contrast, hippocampus showed strong connectivity within the MTL including entorhinal cortex, the ventral stream including the left $\left(\mathrm{MNI}_{x, y, z}=-30,-67,-7\right)$ and right $\left(\mathrm{MNI}_{x, y, z}=33\right.$, $-58,-10)$ fusiform gyrus, left $\left(\mathrm{MNI}_{x, y, z}=-9,-88,2\right)$ and right $\left(\mathrm{MNI}_{x, y, z}=9,-55,11\right)$ calcarine fissure, and left $\left(\mathrm{MNI}_{x, y, z}=-9\right.$, $-49,2)$ and right $\left(\mathrm{MNI}_{x, y, z}=9,-61,2\right)$ lingual gyrus.

Young adults showed an average connectivity of value of $-0.020 \pm 0.03$ between hippocampus/default network $(p=$ $0.55)$ and $0.14 \pm 0.03$ between entorhinal/default network $(p<$ $0.001)$, using a one-sample $t$ test. Older adults showed an average connectivity value of $0.0035 \pm 0.01$ between hippocampus/default network $(p=0.79)$ and $0.084 \pm 0.02$ with entorhinal cortex/default network $(p<0.001)$, using a one-sample $t$ test. A one-tailed $t$ test showed a trend for reduced entorhinal/default- 
Table 3. Control analyses of $A \boldsymbol{\beta}-$ and $A \boldsymbol{\beta}+$ older adults

\begin{tabular}{|c|c|c|c|}
\hline Model & & Hippocampus & $\mathrm{EC}$ \\
\hline \multicolumn{4}{|c|}{ Task-based fMRI activity: $A \beta-$ vs $A \beta+$ older adults } \\
\hline $\begin{array}{l}\text { Model } 1 \\
\quad \text { Covariates }\end{array}$ & $\begin{array}{l}\text { Amyloid }(A \beta-/ A \beta+) \\
\text { None }\end{array}$ & $p=0.91$ & $p=0.024$ \\
\hline Model 2 & Amyloid $(A \beta-/ A \beta+)$ & $p=0.26$ & $p=0.032$ \\
\hline \multirow[t]{5}{*}{ Covariates } & APOE4 status & $p=0.23$ & $p=0.61$ \\
\hline & Age & $p=0.025$ & $p=0.86$ \\
\hline & Gender & $p=0.19$ & $p=0.25$ \\
\hline & Memory $\left(d^{\prime}\right)$ & $p=0.076$ & $p=0.80$ \\
\hline & Gray matter & $p=0.068$ & $p=0.88$ \\
\hline \multicolumn{4}{|c|}{ Resting-state connectivity: $A \beta-$ vs $A \beta+$ older adults } \\
\hline $\begin{array}{l}\text { Model } 1 \\
\quad \text { Covariates }\end{array}$ & $\begin{array}{l}\text { Amyloid }(A \beta-/ A \beta+) \\
\text { None }\end{array}$ & $p=0.31$ & $p=0.063$ \\
\hline Model 2 & Amyloid $(A \beta-/ A \beta+)$ & $p=0.24$ & $p=0.14$ \\
\hline \multirow[t]{5}{*}{ Covariates } & APOE4 status & $p=0.20$ & $p=0.30$ \\
\hline & Age & $p=0.25$ & $p=0.11$ \\
\hline & Gender & $p=0.32$ & $p=0.49$ \\
\hline & Memory $\left(d^{\prime}\right)$ & $p=0.26$ & $p=0.26$ \\
\hline & Gray matter & $p=0.21$ & $p=0.27$ \\
\hline
\end{tabular}

The top half of the table shows control analyses of hippocampal and entorhinal activity (EC) in older adults with low $(\mathrm{A} \beta-)$ and high $(\mathrm{A} \beta+)$ amounts of amyloid- $\beta$ deposition without covariates (Model 1 ) and controlling for APOE4 status, age, gender, memory performance $\left(d^{\prime}\right)$, and gray matter using hippocampal volume/entorhinal thickness (Model 2). The bottom half shows two similar models using default-network connectivity as the dependent variable and comparing hippocampal and entorhinal seeds.

network connectivity in older adults, when compared with young $(p=0.056)$. A $\beta$ - older adults showed an average connectivity value of $-0.003 \pm 0.02$ between hippocampus/default network $(p=0.88)$ and $0.11 \pm 0.02$ between entorhinal/default network $(p<0.001) . \mathrm{A} \beta+$ older adults showed an average connectivity value of $0.01 \pm 0.02$ between hippocampus/default network $(p=0.52)$ and $0.060 \pm 0.02$ with entorhinal cortex/default network $(p=0.015)$. A one-tailed $t$ test showed a trend for reduced entorhinal/default-network connectivity in $\mathrm{A} \beta+$ when compared with $\mathrm{A} \beta-$ older adults $(p=0.063)$. Next, we conducted a connectivity analysis controlling for APOE4 status, age, $d^{\prime}$, gender, and gray matter (hippocampal volume or entorhinal thickness; Table 3). Originally, we observed a trending connectivity difference $(p=0.063)$ between $\mathrm{A} \beta-$ and $\mathrm{A} \beta+$ older adults (Table 3 ). When simultaneously controlling for each of these variables, the significance dropped $(p=0.14)$, presumably due to decreased power. These analyses confirm that entorhinal cortex-but not hippocampus-is functionally connected to the default network. Furthermore, these analyses suggest that amyloid- $\beta$-related changes in the entorhinal cortex are more clearly detected by task-evoked fMRI than resting-state connectivity.

\section{Discussion}

This study provides evidence that neocortical amyloid- $\beta$ deposition in cognitively normal older adults is associated with functional alterations in the MTL. Aging is associated with reduced ability to modulate MTL activity more generally; that is, hippocampus showed age-related loss of activation and entorhinal cortex showed age-related loss of deactivation during an episodic memory task. Furthermore, among older adults, amyloid- $\beta$ deposition was associated with reduced deactivations in entorhinal regions functionally connected with the default network. Both age and amyloid- $\beta$ deposition contribute to disrupted activity and connectivity between entorhinal cortex and neocortical regions of the default network, but our findings suggest that agerelated failure to deactivate entorhinal cortex is in part due to $\mathrm{AD}$-related pathology.
We found that aging reduced hippocampal activations and entorhinal deactivations when comparing young and older adults. These age-related changes are consistent with fMRI studies that reported reduced MTL activity in older adults during encoding and retrieval (Daselaar et al., 2003; Gutchess et al., 2005; Spreng et al., 2010). The dissociation between hippocampal activations and entorhinal deactivations is consistent with the view that distinct MTL subregions support specific memory functions (Daselaar et al., 2006; Ranganath and Ritchey, 2012). Age-related changes in both hippocampus and entorhinal cortex were also detectable in the absence of amyloid deposition. In line with previous aging studies, young adults showed better memory performance and more gray matter compared with older adults (Salthouse et al., 2000; Park et al., 2002; Rodrigue and Raz, 2004). Thus, age-related decline of memory might in part be explained by a reduced ability to modulate MTL activity and age-related loss of gray matter that is detectable in $\mathrm{A} \beta$ - older adults.

A handful of fMRI studies have reported an influence of amyloid deposition on encoding-related activity in the default network (Sperling et al., 2009; Kennedy et al., 2012; Mormino et al., 2012; Oh and Jagust, 2013; Vannini et al., 2013b). Recently, our group reported amyloid-related alterations in posteromedial cortex during encoding and retrieval, but not in hippocampus (Vannini et al., 2012, 2013a). Using a novel paradigm (Huijbers et al., 2013) and an independent group of young and older adults, we observed here an amyloid-related dissociation between hippocampus and entorhinal cortex. Interestingly, entorhinal cortex showed deactivations during both encoding and retrieval, suggesting it performs a similar function in both memory phases, distinct from posteromedial cortex (Huijbers et al., 2012). Together, these findings suggest that neocortical amyloid deposition is associated with functional alterations within the MTL. Nevertheless, it remains possible that low levels of amyloid deposition in the MTL or oligomeric forms, not detectable on PET imaging, contribute to these functional alterations.

The amyloid- $\beta$-related loss of deactivation in entorhinal cortex was similar across both encoding and retrieval phases of the fMRI memory task. Aberrant activity in the cortical regions of the default network has repeatedly been observed in $\mathrm{A} \beta+$ cognitively normal older adults and in early $\mathrm{AD}$, using either task-based activity (Sperling et al., 2009; Kennedy et al., 2012; Schwindt et al., 2013; Vannini et al., 2013) or resting-state connectivity (Rombouts et al., 2005; Hedden et al., 2009; Mormino et al., 2011). We also found aberrant entorhinal activity and trending changes in default-network connectivity associated with amyloid- $\beta$ deposition. This subtle loss in default-network connectivity supports the supposition that default-network connectivity changes before clinical symptoms of AD manifest (Sperling, 2011; Chhatwal et al., 2013; Sheline and Raichle, 2013). Our results further suggest that in clinically normal older adults, amyloid- $\beta$ impacts entorhinal activity and connectivity, while previous fMRI studies have primarily found amyloid-related changes in the neocortex.

Importantly, we found a main effect amyloid- $\beta$ status, but no interaction with a specific component of the memory task. It remains possible that we have insufficient power to detect an interaction, and thus, that in preclinical $\mathrm{AD}$, encoding-related activity is impacted to a greater degree (Braskie et al., 2009; Vannini et al., 2013). Alternatively, some neocortical regions, such as posteromedial cortex, are more strongly modulated during a specific memory phase and might signal aberrant activity more clearly during encoding (Huijbers et al., 2012). Yet, the consistent pattern across different components of the memory task suggests that amyloid- $\beta$-related dysfunction in the entorhinal cortex re- 


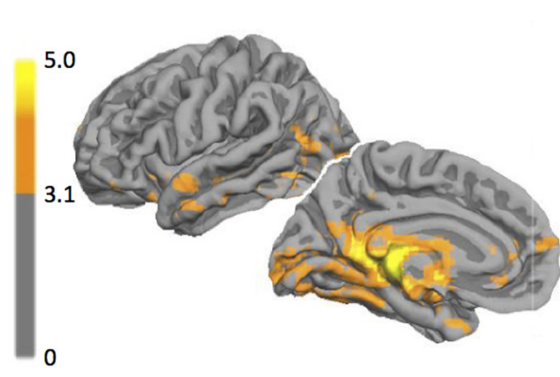

Hippocampal connectivity

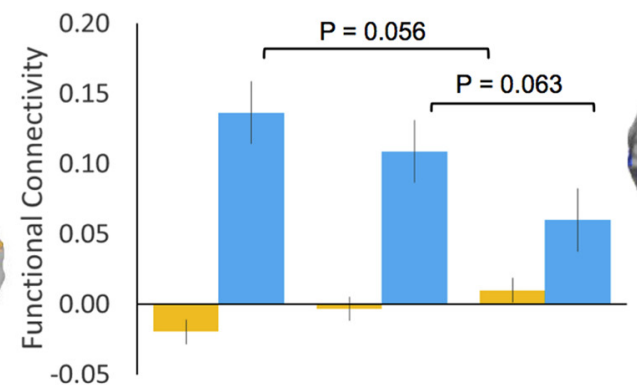

YNG $A \beta-\quad A \beta+$

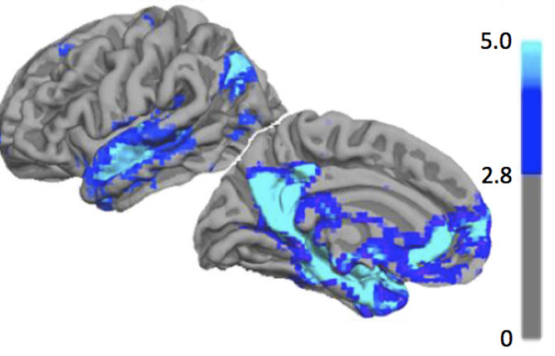

Entorhinal connectivity

Figure 4. Resting-state functional connectivity of hippocampus and entorhinal cortex. On the left, in yellow, statistical maps showing regions functionally connected with hippocampus ( $p<$ 0.05 , FDR-corrected, minimum cluster extent 10 voxels). On the right, in blue, statistical maps showing regions functionally connected with entorhinal cortex ( $p<0.05$, FDR-corrected, minimum cluster extent 10 voxels). In the middle, quantified functional connectivity between hippocampus/default network in yellow and entorhinal cortex/default network in blue, plotted separately for young (YNG) and older adults with low $(A \beta-)$ and high $(A \beta+)$ amounts of amyloid- $\beta$ deposition. Comparisons involving young adults indicate a trend between young and the average of all older adults.

flects a general dysfunction of the default network, which has been linked to multiple cognitive functions (Buckner et al., 2008; Andrews-Hanna, 2012; Anticevic et al., 2012). This latter interpretation fits with non-mnemonic studies that found age- and AD-related change in default-network activity (Lustig et al., 2003; Park et al., 2010). In the absence of evidence for a specific detriment to memory encoding or retrieval, we interpret these findings as a common detrimental influence of amyloid- $\beta$ on the entorhinal cortex and default network.

$\mathrm{A} \beta-$ and $\mathrm{A} \beta+$ cognitively normal older adults were similar in terms of demographics, except APOE4 status. APOE4 status, age, gender, $d^{\prime}$, and gray matter did not account for amyloid-related dysfunction of the entorhinal cortex (Table 3). Amyloid- $\beta$ accounts for approximately a third of the difference between young and older adults. Yet, the majority of age-related functional alteration in entorhinal cortex (and in hippocampus) remains unaccounted for. Other age-related factors, such as vascular disease, inflammation, tau aggregation, and oligomeric forms of amyloid- $\beta$, may explain these age-related changes in MTL activity (D'Esposito et al., 2003; Hedden and Gabrieli, 2004; Fotuhi et al., 2012; Jagust, 2013). Furthermore, levels of amyloid deposition below the threshold of detection might co-occur with these other age-related factors and together explain age-related functional alterations within the MTL.

Amyloid deposition precedes the manifestation of clinical symptom by a decade or more (Jack et al., 2013). Previous reports suggest that the influence of amyloid- $\beta$ deposition on crosssectional memory performance among clinically normal adults is subtle (Rentz et al., 2011; Hedden et al., 2012, 2013; Rodrigue et al., 2012; Lim et al., 2013). We found that hippocampal activity was not different between $\mathrm{A} \beta-$ and $\mathrm{A} \beta+$ older adults. Thus, it is possible that amyloid-related hippocampal dysfunction is not present until memory impairment is clearly detectable, at the stage of early mild cognitive impairment (MCI; Sperling et al., 2009; O’Brien et al., 2010). Several recent longitudinal studies have demonstrated that amyloid deposition in cognitively normal older adults is related to gray matter atrophy, and higher rates of cognitive decline (Chételat et al., 2012; Lim et al., 2012; Knopman et al., 2013a; Villemagne et al., 2013). Longitudinal studies need to examine amyloid-related dysfunction in both hippocampus and entorhinal cortex to clarify why some $\mathrm{A} \beta+$ older adults progress to MCI while others remain cognitively normal.

Together, amyloid- $\beta$ and tau deposition are the hallmarks of AD pathology (Braak and Braak, 1991; Gómez-Isla et al., 1996;
Tiraboschi et al., 2004). Our finding that neocortical amyloid- $\beta$ deposition is associated with entorhinal dysfunction may have implications for our understanding of these two pathological processes. CSF markers and postmortem data from the entorhinal cortex indicate that tau aggregates begin in mid-life, years before amyloid- $\beta$ deposits in the neocortex (Forsberg et al., 2008; Fagan et al., 2009; Nelson et al., 2012). Based on the consistency between PET amyloid imaging and postmortem counts of plaques and tangles, it is likely that many $\mathrm{A} \beta+$ older adults also harbor tau in entorhinal cortex (Braak and Braak, 1991; Ikonomovic et al., 2008; Sperling et al., 2011). Thus, the link between neocortical amyloid- $\beta$ and aberrant entorhinal activity could be mediated by tau aggregation or reflect the convergence of amyloid- $\beta$ and tau-mediated pathways (Mesulam, 1999; Desikan et al., 2012).

Our connectivity analyses confirm that entorhinal cortex is preferentially connected to the default network (Ward et al., 2014). The default network is also vulnerable to amyloid- $\beta$ accumulation, perhaps due to high levels of neuronal activity (Gusnard and Raichle, 2001; Buckner et al., 2005; Bero et al., 2011; Jagust and Mormino, 2011). It remains contested whether the vulnerability of the default network is due to high levels of activity, or strong connectivity, and whether other regions outside of the default network are similarly vulnerable to amyloid- $\beta$ accumulation. Interestingly, tau has recently been shown to propagate via synaptic connections (Liu et al., 2012; de Calignon et al., 2012). The vulnerability of the default network in AD could reflect the convergence of amyloid- $\beta$ - and tau-mediated dysfunction driven by the combination of active neurons and entorhinal connectivity. Thus, although current models of $\mathrm{AD}$ progression propose that amyloid- $\beta$ deposition precedes functional abnormality (Jack et al., 2013), aberrant function of the entorhinal cortex and default network might facilitate deposition of amyloid- $\beta$. Therefore, it remains unclear whether amyloid- $\beta$ results in functional alterations or vice versa. The recent advent of PET tau imaging in humans, in combination with PET amyloid imaging, may identify tau propagation from the entorhinal cortex as a key factor and clarify the role of functional alterations in default network in the setting of early amyloid- $\beta$ deposition.

In summary, aging in the absence of amyloid deposition has a detrimental influence on activity in both hippocampus and entorhinal cortex. Cognitively normal older adults with elevated amyloid- $\beta$ deposition in the neocortex display additional functional abnormalities in entorhinal cortex and its connections to the default network. In contrast, hippocampal activity is affected 
by aging, but does not show a detrimental association with amyloid- $\beta$. The association between neocortical amyloid- $\beta$ and subtle dysfunction within the MTL memory system may provide an important link between amyloid- $\beta$ pathology and the emergence of episodic memory impairment during the later stages of preclinical $\mathrm{AD}$.

\section{References}

Aizenstein HJ, Nebes RD, Saxton JA, Price JC, Mathis CA, Tsopelas ND, Ziolko SK, James JA, Snitz BE, Houck PR, Bi W, Cohen AD, Lopresti BJ, DeKosky ST, Halligan EM, Klunk WE (2008) Frequent amyloid deposition without significant cognitive impairment among the elderly. Arch Neurol 65:1509-1517. CrossRef Medline

Andrews-Hanna JR (2012) The brain's default network and its adaptive role in internal mentation. Neuroscientist 18:251-270. CrossRef Medline

Anticevic A, Cole MW, Murray JD, Corlett PR, Wang XJ, Krystal JH (2012) The role of default network deactivation in cognition and disease. Trends Cogn Sci 16:584-592. CrossRef Medline

Becker JA, Hedden T, Carmasin J, Maye J, Rentz DM, Putcha D, Fischl B, Greve DN, Marshall GA, Salloway S, Marks D, Buckner RL, Sperling RA, Johnson KA (2011) Amyloid-beta associated cortical thinning in clinically normal elderly. Ann Neurol 69:1032-1042. CrossRef Medline

Bero AW, Yan P, Roh JH, Cirrito JR, Stewart FR, Raichle ME, Lee JM, Holtzman DM (2011) Neuronal activity regulates the regional vulnerability to amyloid-[beta] deposition. Nat Neurosci 14:750-756. CrossRef Medline

Braak H, Braak E (1991) Neuropathological stageing of Alzheimer-related changes. Acta Neuropathol 82:239-259. CrossRef Medline

Brainard DH (1997) The Psychophysics Toolbox. Spat Vis 10:433-436. CrossRef Medline

Braskie MN, Small GW, Bookheimer SY (2009) Entorhinal cortex structure and functional MRI response during an associative verbal memory task. Hum Brain Mapp 30:3981-3992. CrossRef Medline

Buckner RL, Snyder AZ, Shannon BJ, LaRossa G, Sachs R, Fotenos AF, Sheline YI, Klunk WE, Mathis CA, Morris JC, Mintun MA (2005) Molecular, structural, and functional characterization of Alzheimer's disease: evidence for a relationship between default activity, amyloid, and memory. J Neurosci 25:7709-7717. CrossRef Medline

Buckner RL, Andrews-Hanna JR, Schacter DL (2008) The brain's default network: anatomy, function, and relevance to disease. Ann N Y Acad Sci 1124:1-38. CrossRef Medline

Chételat G, Villemagne VL, Villain N, Jones G, Ellis KA, Ames D, Martins RN, Masters CL, Rowe CC, Group AR (2012) Accelerated cortical atrophy in cognitively normal elderly with high beta-amyloid deposition. Neurology 78:477-484. CrossRef Medline

Chhatwal JP, Schultz AP, Johnson K, Benzinger TL, Jack C Jr, Ances BM, Sullivan CA, Salloway SP, Ringman JM, Koeppe RA, Marcus DS, Thompson P, Saykin AJ, Correia S, Schofield PR, Rowe CC, Fox NC, Brickman AM, Mayeux R, McDade E, et al. (2013) Impaired default network functional connectivity in autosomal dominant Alzheimer disease. Neurology 81:736-744. CrossRef Medline

Clark CM, Schneider JA, Bedell BJ, Beach TG, Bilker WB, Mintun MA, Pontecorvo MJ, Hefti F, Carpenter AP, Flitter ML, Krautkramer MJ, Kung HF, Coleman RE, Doraiswamy PM, Fleisher AS, Sabbagh MN, Sadowsky CH, Reiman EP, Zehntner SP, Skovronsky DM, et al. (2011) Use of florbetapir-PET for imaging beta-amyloid pathology. JAMA 305:275283. CrossRef Medline

Dale AM, Greve DN, Burock MA (1999) Optimal stimulus sequences for event-related fMRI. In: 5th International Conference on Functional Mapping of the Human Brain, Duesseldorf, Germany, June.

Daselaar SM, Veltman DJ, Rombouts SA, Raaijmakers JG, Jonker C (2003) Neuroanatomical correlates of episodic encoding and retrieval in young and elderly subjects. Brain 126:43-56. CrossRef Medline

Daselaar SM, Fleck MS, Cabeza R (2006) Triple dissociation in the medial temporal lobes: recollection, familiarity, and novelty. J Neurophysiol 96: 1902-1911. CrossRef Medline

de Calignon A, Polydoro M, Suárez-Calvet M, William C, Adamowicz DH, Kopeikina KJ, Pitstick R, Sahara N, Ashe KH, Carlson GA, Spires-Jones TL, Hyman BT (2012) Propagation of tau pathology in a model of early Alzheimer's disease. Neuron 73:685-697. CrossRef Medline

Desikan RS, McEvoy LK, Thompson WK, Holland D, Brewer JB, Aisen PS, Sperling RA, Dale AM, Alzheimer's Disease Neuroimaging I (2012) Am- yloid-beta-associated clinical decline occurs only in the presence of elevated P-tau. Arch Neurol 69:709-713. CrossRef Medline

D'Esposito M, Deouell LY, Gazzaley A (2003) Alterations in the BOLD fMRI signal with ageing and disease: a challenge for neuroimaging. Nat Rev Neurosci 4:863-872. CrossRef Medline

Du AT, Schuff N, Zhu XP, Jagust WJ, Miller BL, Reed BR, Kramer JH, Mungas D, Yaffe K, Chui HC, Weiner MW (2003) Atrophy rates of entorhinal cortex in $\mathrm{AD}$ and normal aging. Neurology 60:481-486. CrossRef Medline

Eickhoff SB, Paus T, Caspers S, Grosbras MH, Evans AC, Zilles K, Amunts K (2007) Assignment of functional activations to probabilistic cytoarchitectonic areas revisited. Neuroimage 36:511-521. CrossRef Medline

Fagan AM, Mintun MA, Shah AR, Aldea P, Roe CM, Mach RH, Marcus D, Morris JC, Holtzman DM (2009) Cerebrospinal fluid tau and ptau181 increase with cortical amyloid deposition in cognitively normal individuals: implications for future clinical trials of Alzheimer's disease. EMBO Mol Med 1:371-380. CrossRef Medline

Fernández G, Brewer JB, Zhao Z, Glover GH, Gabrieli JD (1999) Level of sustained entorhinal activity at study correlates with subsequent cuedrecall performance: a functional magnetic resonance imaging study with high acquisition rate. Hippocampus 9:35-44. CrossRef Medline

Forsberg A, Engler H, Almkvist O, Blomquist G, Hagman G, Wall A, Ringheim A, Långström B, Nordberg A (2008) PET imaging of amyloid deposition in patients with mild cognitive impairment. Neurobiol Aging 29:1456-1465. CrossRef Medline

Fotuhi M, Do D, Jack C (2012) Modifiable factors that alter the size of the hippocampus with ageing. Nat Rev Neurol 8:189-202. CrossRef Medline

Fox MD, Snyder AZ, Vincent JL, Corbetta M, Van Essen DC, Raichle ME (2005) The human brain is intrinsically organized into dynamic, anticorrelated functional networks. Proc Natl Acad Sci U S A 102:9673-9678. CrossRef Medline

Gómez-Isla T, Price JL, McKeel DW Jr, Morris JC, Growdon JH, Hyman BT (1996) Profound loss of layer II entorhinal cortex neurons occurs in very mild Alzheimer's disease. J Neurosci 16:4491-4500. Medline

Gusnard DA, Raichle ME (2001) Searching for a baseline: functional imaging and the resting human brain. Nat Rev Neurosci 2:685-694. CrossRef Medline

Gutchess AH, Welsh RC, Hedden T, Bangert A, Minear M, Liu LL, Park DC (2005) Aging and the neural correlates of successful picture encoding: frontal activations compensate for decreased medial-temporal activity. J Cogn Neurosci 17:84-96. CrossRef Medline

Hedden T, Gabrieli JD (2004) Insights into the ageing mind: a view from cognitive neuroscience. Nat Rev Neurosci 5:87-96. CrossRef Medline

Hedden T, Van Dijk KR, Becker JA, Mehta A, Sperling RA, Johnson KA, Buckner RL (2009) Disruption of functional connectivity in clinically normal older adults harboring amyloid burden. J Neurosci 29:1268612694. CrossRef Medline

Hedden T, Mormino EC, Amariglio RE, Younger AP, Schultz AP, Becker JA, Buckner RL, Johnson KA, Sperling RA, Rentz DM (2012) Cognitive profile of amyloid burden and white matter hyperintensities in cognitively normal older adults. J Neurosci 32:16233-16242. CrossRef Medline

Hedden T, Oh H, Younger AP, Patel TA (2013) Meta-analysis of amyloidcognition relations in cognitively normal older adults. Neurology 80 : 1341-1348. CrossRef Medline

Huijbers W, Vannini P, Sperling RA, Pennartz CM, Cabeza R, Daselaar SM (2012) Explaining the encoding/retrieval flip: memory-related deactivations and activations in the posteromedial cortex. Neuropsychologia 50 : 3764-3774. CrossRef Medline

Huijbers W, Schultz AP, Vannini P, McLaren DG, Wigman SE, Ward AM, Hedden T, Sperling RA (2013) The encoding/retrieval flip: interactions between memory performance and memory stage and relationship to intrinsic cortical networks. J Cogn Neurosci 25:1163-1179. CrossRef Medline

Ikonomovic MD, Klunk WE, Abrahamson EE, Mathis CA, Price JC, Tsopelas ND, Lopresti BJ, Ziolko S, Bi W, Paljug WR, Debnath ML, Hope CE, Isanski BA, Hamilton RL, DeKosky ST (2008) Post-mortem correlates of in vivo PiB-PET amyloid imaging in a typical case of Alzheimer's disease. Brain 131:1630-1645. CrossRef Medline

Jack CR Jr, Knopman DS, Jagust WJ, Petersen RC, Weiner MW, Aisen PS, Shaw LM, Vemuri P, Wiste HJ, Weigand SD, Lesnick TG, Pankratz VS, Donohue MC, Trojanowski JQ (2013) Tracking pathophysiological 
processes in Alzheimer's disease: an updated hypothetical model of dynamic biomarkers. Lancet Neurol 12:207-216. CrossRef Medline

Jagust W (2013) Vulnerable neural systems and the borderland of brain aging and neurodegeneration. Neuron 77:219-234. CrossRef Medline

Jagust WJ, Mormino EC (2011) Lifespan brain activity, beta-amyloid, and Alzheimer's disease. Trends Cogn Sci 15:520-526. CrossRef Medline

Jagust WJ, Bandy D, Chen K, Foster NL, Landau SM, Mathis CA, Price JC, Reiman EM, Skovronsky D, Koeppe RA (2010) The Alzheimer's Disease Neuroimaging Initiative positron emission tomography core. Alzheimers Dement 6:221-229. CrossRef Medline

Johnson KA, Gregas M, Becker JA, Kinnecom C, Salat DH, Moran EK, Smith EE, Rosand J, Rentz DM, Klunk WE, Mathis CA, Price JC, Dekosky ST, Fischman AJ, Greenberg SM (2007) Imaging of amyloid burden and distribution in cerebral amyloid angiopathy. Ann Neurol 62:229-234. CrossRef Medline

Kahn I, Andrews-Hanna JR, Vincent JL, Snyder AZ, Buckner RL (2008) Distinct cortical anatomy linked to subregions of the medial temporal lobe revealed by intrinsic functional connectivity. J Neurophysiol 100: 129-139. CrossRef Medline

Kennedy KM, Rodrigue KM, Devous MD Sr, Hebrank AC, Bischof GN, Park DC (2012) Effects of beta-amyloid accumulation on neural function during encoding across the adult lifespan. Neuroimage 62:1-8. CrossRef Medline

Knopman DS, Jack CR Jr, Wiste HJ, Weigand SD, Vemuri P, Lowe VJ, Kantarci K, Gunter JL, Senjem ML, Mielke MM, Roberts RO, Boeve BF, Petersen RC (2013a) Selective worsening of brain injury biomarker abnormalities in cognitively normal elderly persons with beta-amyloidosis. JAMA Neurol 70:1030-1038. CrossRef Medline

Knopman DS, Jack CR Jr, Wiste HJ, Weigand SD, Vemuri P, Lowe VJ, Kantarci K, Gunter JL, Senjem ML, Mielke MM, Roberts RO, Boeve BF, Petersen RC (2013b) Brain injury biomarkers are not dependent on $\beta$-amyloid in normal elderly. Ann Neurol 73:472-480. CrossRef Medline

Lacy JW, Stark CE (2012) Intrinsic functional connectivity of the human medial temporal lobe suggests a distinction between adjacent MTL cortices and hippocampus. Hippocampus 22:2290-2302. CrossRef Medline

Libby LA, Ekstrom AD, Ragland JD, Ranganath C (2012) Differential connectivity of perirhinal and parahippocampal cortices within human hippocampal subregions revealed by high-resolution functional imaging. J Neurosci 32:6550-6560. CrossRef Medline

Lim YY, Ellis KA, Pietrzak RH, Ames D, Darby D, Harrington K, Martins RN, Masters CL, Rowe C, Savage G, Szoeke C, Villemagne VL, Maruff P, Group AR (2012) Stronger effect of amyloid load than APOE genotype on cognitive decline in healthy older adults. Neurology 79:1645-1652. CrossRef Medline

Lim YY, Pietrzak RH, Ellis KA, Jaeger J, Harrington K, Ashwood T, Szoeke C, Martins RN, Bush AI, Masters CL, Rowe CC, Villemagne VL, Ames D, Darby D, Maruff P (2013) Rapid decline in episodic memory in healthy older adults with high amyloid-beta. J Alzheimer's Dis 33:675-679. CrossRef Medline

Liu L, Drouet V, Wu JW, Witter MP, Small SA, Clelland C, Duff K (2012) Trans-synaptic spread of tau pathology in vivo. PLoS One 7:e31302. CrossRef Medline

Lustig C, Snyder AZ, Bhakta M, O’Brien KC, McAvoy M, Raichle ME, Morris JC, Buckner RL (2003) Functional deactivations: change with age and dementia of the Alzheimer type. Proc Natl Acad Sci U S A 100:1450414509. CrossRef Medline

MacMillan NA, Creelman CD (2005) Detection theory: a user's guide, Ed 2. Mahwah, NJ: Erlbaum.

Maldjian JA, Laurienti PJ, Kraft RA, Burdette JH (2003) An automated method for neuroanatomic and cytoarchitectonic atlas-based interrogation of fMRI data sets. Neuroimage 19:1233-1239. CrossRef Medline

Mathis CA, Bacskai BJ, Kajdasz ST, McLellan ME, Frosch MP, Hyman BT, Holt DP, Wang Y, Huang GF, Debnath ML, Klunk WE (2002) A lipophilic thioflavin-T derivative for positron emission tomography (PET) imaging of amyloid in brain. Bioorg Med Chem Lett 12:295-298. CrossRef Medline

Mesulam MM (1999) Neuroplasticity failure in Alzheimer's disease: bridging the gap between plaques and tangles. Neuron 24:521-529. CrossRef Medline

Mintun MA, Larossa GN, Sheline YI, Dence CS, Lee SY, Mach RH, Klunk WE, Mathis CA, DeKosky ST, Morris JC (2006) [11C]PIB in a nondemented population: potential antecedent marker of Alzheimer disease. Neurology 67:446-452. CrossRef Medline

Mormino EC, Smiljic A, Hayenga AO, Onami SH, Greicius MD, Rabinovici GD, Janabi M, Baker SL, Yen IV, Madison CM, Miller BL, Jagust WJ (2011) Relationships between beta-amyloid and functional connectivity in different components of the default mode network in aging. Cereb Cortex 21:2399-2407. CrossRef Medline

Mormino EC, Brandel MG, Madison CM, Marks S, Baker SL, Jagust WJ (2012) Abeta deposition in aging is associated with increases in brain activation during successful memory encoding. Cereb Cortex 22:18131823. CrossRef Medline

Nelson PT, Alafuzoff I, Bigio EH, Bouras C, Braak H, Cairns NJ, Castellani RJ, Crain BJ, Davies P, Del Tredici K, Duyckaerts C, Frosch MP, Haroutunian V, Hof PR, Hulette CM, Hyman BT, Iwatsubo T, Jellinger KA, Jicha GA, Kövari E, et al. (2012) Correlation of Alzheimer disease neuropathologic changes with cognitive status: a review of the literature. J Neuropathol Exp Neurol 71:362-381. CrossRef Medline

O’Brien JL, O'Keefe KM, LaViolette PS, DeLuca AN, Blacker D, Dickerson BC, Sperling RA (2010) Longitudinal fMRI in elderly reveals loss of hippocampal activation with clinical decline. Neurology 74:1969-1976. CrossRef Medline

Oh H, Jagust WJ (2013) Frontotemporal network connectivity during memory encoding is increased with aging and disrupted by beta-amyloid. J Neurosci 33:18425-18437. CrossRef Medline

Park DC, Lautenschlager G, Hedden T, Davidson NS, Smith AD, Smith PK (2002) Models of visuospatial and verbal memory across the adult life span. Psychol Aging 17:299-320. CrossRef Medline

Park DC, Polk TA, Hebrank AC, Jenkins LJ (2010) Age differences in default mode activity on easy and difficult spatial judgment tasks. Front Hum Neurosci 3:75. Medline

Petersen RC, Jack CR Jr, Xu YC, Waring SC, O’Brien PC, Smith GE, Ivnik RJ, Tangalos EG, Boeve BF, Kokmen E (2000) Memory and MRI-based hippocampal volumes in aging and AD. Neurology 54:581-587. CrossRef Medline

Price JC, Klunk WE, Lopresti BJ, Lu X, Hoge JA, Ziolko SK, Holt DP, Meltzer CC, DeKosky ST, Mathis CA (2005) Kinetic modeling of amyloid binding in humans using PET imaging and Pittsburgh Compound-B. J Cereb Blood Flow Metab 25:1528-1547. CrossRef Medline

Price JL, McKeel DW Jr, Buckles VD, Roe CM, Xiong C, Grundman M, Hansen LA, Petersen RC, Parisi JE, Dickson DW, Smith CD, Davis DG, Schmitt FA, Markesbery WR, Kaye J, Kurlan R, Hulette C, Kurland BF, Higdon R, Kukull W, et al. (2009) Neuropathology of nondemented aging: presumptive evidence for preclinical Alzheimer disease. Neurobiol Aging 30:1026-1036. CrossRef Medline

Raichle ME, MacLeod AM, Snyder AZ, Powers WJ, Gusnard DA, Shulman GL (2001) A default mode of brain function. Proc Natl Acad Sci U S A 98:676-682. CrossRef Medline

Ranganath C, Ritchey M (2012) Two cortical systems for memory-guided behaviour. Nat Rev Neurosci 13:713-726. CrossRef Medline

Rentz DM, Amariglio RE, Becker JA, Frey M, Olson LE, Frishe K, Carmasin J, Maye JE, Johnson KA, Sperling RA (2011) Face-name associative memory performance is related to amyloid burden in normal elderly. Neuropsychologia 49:2776-2783. CrossRef Medline

Resnick SM, Sojkova J (2011) Amyloid imaging and memory change for prediction of cognitive impairment. Alzheimers Res Ther 3:3. CrossRef Medline

Rodrigue KM, Raz N (2004) Shrinkage of the entorhinal cortex over five years predicts memory performance in healthy adults. J Neurosci 24:956963. CrossRef Medline

Rodrigue KM, Kennedy KM, Devous MD Sr, Rieck JR, Hebrank AC, DiazArrastia R, Mathews D, Park DC (2012) beta-Amyloid burden in healthy aging: regional distribution and cognitive consequences. Neurology 78:387-395. CrossRef Medline

Roe CM, Fagan AM, Grant EA, Hassenstab J, Moulder KL, Maue Dreyfus D, Sutphen CL, Benzinger TLS, Mintun MA, Holtzman DM, Morris JC (2013) Amyloid imaging and CSF biomarkers in predicting cognitive impairment up to 7.5 years later. Neurology 80:1784-1791. CrossRef Medline

Rombouts SA, Barkhof F, Goekoop R, Stam CJ, Scheltens P (2005) Altered resting state networks in mild cognitive impairment and mild Alzheimer's disease: an fMRI study. Hum Brain Mapp 26:231-239. CrossRef Medline Rowe CC, Ellis KA, Rimajova M, Bourgeat P, Pike KE, Jones G, Fripp J, 
Tochon-Danguy H, Morandeau L, O'Keefe G, Price R, Raniga P, Robins P, Acosta O, Lenzo N, Szoeke C, Salvado O, Head R, Martins R, Masters CL, et al. (2010) Amyloid imaging results from the Australian Imaging, Biomarkers and Lifestyle (AIBL) study of aging. Neurobiol Aging 31: 1275-1283. CrossRef Medline

Salthouse TA, Toth J, Daniels K, Parks C, Pak R, Wolbrette M, Hocking KJ (2000) Effects of aging on efficiency of task switching in a variant of the trail making test. Neuropsychology 14:102-111. CrossRef Medline

Schwindt GC, Chaudhary S, Crane D, Ganda A, Masellis M, Grady CL, Stefanovic B, Black SE (2013) Modulation of the default-mode network between rest and task in Alzheimer's disease. Cereb Cortex 23:1685-1694. CrossRef Medline

Serrano-Pozo A, Frosch MP, Masliah E, Hyman BT (2011) Neuropathological alterations in Alzheimer disease. Cold Spring Harb Perspect Med 1:a006189. CrossRef Medline

Sheline YI, Raichle ME (2013) Resting state functional connectivity in preclinical Alzheimer's disease. Biol Psychiatry 74:340-347. CrossRef Medline

Sheline YI, Raichle ME, Snyder AZ, Morris JC, Head D, Wang S, Mintun MA (2010) Amyloid plaques disrupt resting state default mode network connectivity in cognitively normal elderly. Biol Psychiatry 67:584-587. CrossRef Medline

Small SA, Schobel SA, Buxton RB, Witter MP, Barnes CA (2011) A pathophysiological framework of hippocampal dysfunction in ageing and disease. Nat Rev Neurosci 12:585-601. CrossRef Medline

Sperling R (2011) Potential of functional MRI as a biomarker in early Alzheimer's disease. Neurobiol Aging 32 [Suppl 1]:S37-S43.

Sperling RA, Aisen PS, Beckett LA, Bennett DA, Craft S, Fagan AM, Iwatsubo T, Jack CR Jr, Kaye J, Montine TJ, Park DC, Reiman EM, Rowe CC, Siemers E, Stern Y, Yaffe K, Carrillo MC, Thies B, Morrison-Bogorad M, Wagster MV, et al. (2011) Toward defining the preclinical stages of Alzheimer's disease: recommendations from the National Institute on Aging-Alzheimer's Association workgroups on diagnostic guidelines for Alzheimer's disease. Alzheimer's Dement 7:280-292. CrossRef Medline

Sperling RA, Laviolette PS, O'Keefe K, O’Brien J, Rentz DM, Pihlajamaki M, Marshall G, Hyman BT, Selkoe DJ, Hedden T, Buckner RL, Becker JA, Johnson KA (2009) Amyloid deposition is associated with impaired de- fault network function in older persons without dementia. Neuron 63: 178-188. CrossRef Medline

Spreng RN, Wojtowicz M, Grady CL (2010) Reliable differences in brain activity between young and old adults: a quantitative meta-analysis across multiple cognitive domains. Neurosci Biobehav Rev 34:1178-1194. CrossRef Medline

Tiraboschi P, Hansen LA, Thal LJ, Corey-Bloom J (2004) The importance of neuritic plaques and tangles to the development and evolution of $\mathrm{AD}$. Neurology 62:1984-1989. CrossRef Medline

Van Dijk KR, Hedden T, Venkataraman A, Evans KC, Lazar SW, Buckner RL (2010) Intrinsic functional connectivity as a tool for human connectomics: theory, properties, and optimization. J Neurophysiol 103:297-321. CrossRef Medline

Vannini P, Hedden T, Becker JA, Sullivan C, Putcha D, Rents D, Johnson KA, Sperling RA (2012) Age and amyloid-related alterations in default network habituation to stimulus repetition. Neurobiol Aging 33:1237-1252. CrossRef Medline

Vannini P, Hedden T, Huijbers W, Ward A, Johnson KA, Sperling RA (2013a) The ups and downs of the posteromedial cortex: age- and amyloid-related functional alterations of the encoding/retrieval flip in cognitively normal older adults. Cereb Cortex 23:1317-1328. CrossRef Medline

Vannini, P, Hedden T, Sullivan C, Sperling RA (2013b) Differential functional response in the posteromedial cortices and hippocampus to stimulus repetition during successful memory encoding. Hum Brain Mapp 34:1568-1578. CrossRef Medline

Villemagne VL, Burnham S, Bourgeat P, Brown B, Ellis KA, Salvado O, Szoeke C, Macaulay SL, Martins R, Maruff P, Ames D, Rowe CC, Masters CL, Australian Imaging B, Lifestyle Research G (2013) Amyloid beta deposition, neurodegeneration, and cognitive decline in sporadic Alzheimer's disease: a prospective cohort study. Lancet Neurol 12:357-367. CrossRef Medline

Ward AM, Schultz AP, Huijbers W, Van Dijk KR, Hedden T, Sperling RA (2014) The parahippocampal gyrus links the default-mode cortical network with the medial temporal lobe memory system. Hum Brain Mapp 35:1061-1073. CrossRef Medline 